\title{
Dietary Synbiotics Can Help Relieve the Impacts of Deltamethrin Toxicity of Nile Tilapia Reared at Low Temperatures
}

\author{
Mahmoud S. Gewaily ${ }^{1}{ }^{(D}$, Safaa E. Abdo ${ }^{2}$, Eman M. Moustafa ${ }^{3}$, Marwa F. AbdEl-kader ${ }^{4}$, \\ Ibrahim M. Abd El-Razek ${ }^{5}$, Mohamed El-Sharnouby ${ }^{6}$, Mohamed Alkafafy ${ }^{6} \mathbb{D}$, Sayed Haidar Abbas Raza ${ }^{7} \mathbb{D}$, \\ Mohammed F. El Basuini ${ }^{8,9}$ (D), Hien Van Doan ${ }^{10,11, *(\mathbb{D})}$ and Mahmoud A. O. Dawood ${ }^{5}$ (D)
}

check for updates

Citation: Gewaily, M.S.; Abdo, S.E.; Moustafa, E.M.; AbdEl-kader, M.F.; Abd El-Razek, I.M.; El-Sharnouby, M.; Alkafafy, M.; Raza, S.H.A.; El Basuini, M.F.; Van Doan, H.; et al. Dietary Synbiotics Can Help Relieve the Impacts of Deltamethrin Toxicity of Nile Tilapia Reared at Low Temperatures. Animals 2021, 11, 1790. https://doi.org/10.3390/ani11061790

Academic Editors: Antoni Ibarz,

Marcelino Herrera and

Luis Vargas-Chacoff

Received: 21 April 2021

Accepted: 14 June 2021

Published: 15 June 2021

Publisher's Note: MDPI stays neutral with regard to jurisdictional claims in published maps and institutional affiliations.

Copyright: (c) 2021 by the authors. Licensee MDPI, Basel, Switzerland. This article is an open access article distributed under the terms and conditions of the Creative Commons Attribution (CC BY) license (https:/ / creativecommons.org/licenses/by/ $4.0 /)$.
1 Department of Anatomy and Embryology, Faculty of Veterinary Medicine, Kafrelsheikh University, Kafr El Sheikh 33516, Egypt; drmahmoud_gewaily@yahoo.com

2 Department of Animal Wealth Development, Faculty of Veterinary Medicine, Kafrelsheikh University, Kafr El Sheikh 33516, Egypt; safaa_2m@yahoo.com

3 Department of Fish Diseases and Management, Faculty of Veterinary Medicine Kafrelsheikh University, Kafr El Sheikh 33516, Egypt; emantarek2002@yahoo.com

4 Department of Fish Diseases and Management, Sakha Aquaculture Research Unit, Central Laboratory for Aquaculture Research, A.R.C., Kafr El Sheikh 33516, Egypt; marwa.abdelkader@vet.kfs.edu.eg

5 Department of Animal Production, Faculty of Agriculture, Kafrelsheikh University, Kafr El Sheikh 33516, Egypt; ibrahim.abdelrazek1@agr.kfs.edu.eg (I.M.A.E.-R.); mahmouddawood55@gmail.com (M.A.O.D.)

6 Department of Biotechnology, College of Science, Taif University, P.O. Box 11099, Taif 21944, Saudi Arabia; m.sharnouby@Tu.edu.sa (M.E.-S.); m.kafafy@tu.edu.sa (M.A.)

7 State Key Laboratory of Animal Genetics Breeding \& Reproduction, College of Animal Science and Technology, Northwest A\&F University, Yangling 712100, China; dr.haiderabbasraza@gmail.com

8 Faculty of Desert Agriculture, King Salman International University, South Sinai 46618, Egypt; m_fouad_islam@yahoo.com

9 Department of Animal Production, Faculty of Agriculture, Tanta University, Tanta 31527, Egypt

10 Department of Animal and Aquatic Sciences, Faculty of Agriculture, Chiang Mai University, Chiang Mai 50200, Thailand

11 Science and Technology Research Institute, Chiang Mai University, 239 Huay Keaw Rd., Suthep, Muang, Chiang Mai 50200, Thailand

* Correspondence: hien.d@cmu.ac.th

Simple Summary: The toxic impacts of pesticides and insecticides are strongly correlated with water temperature. Water temperature can increase or decrease the efficacy of toxins and their influence on aquatic organisms. An alternate approach to augmenting fish resistance to ambient deltamethrin (DMT) toxicity and low water temperature via synbiotic feeding was proposed. In this study, fish were allocated into four groups and kept at suboptimal water temperature $\left(21 \pm 2{ }^{\circ} \mathrm{C}\right)$ : control, DMT, synbiotic, and DMT + synbiotic. The results illustrate that including synbiotics in the Nile tilapia diet stimulates the immunity and antioxidant systems in fish, enabling the fish reared at a suboptimal temperature to counteract the immunity suppression and oxidative stress caused by DMT exposure.

Abstract: The optimal water temperature for the normal growth of Nile tilapia is between 26 and $28^{\circ} \mathrm{C}$, and the toxicity of pesticides is strongly related to water temperature. An alternate approach to augmenting the resistance of fish to ambient water toxicity and low water temperature via synbiotic feeding was proposed. In this study, fish were allocated into four groups with 10 fish in each replicate, where they were fed a basal diet or synbiotics $(550 \mathrm{mg} / \mathrm{kg})$ and kept at a suboptimal water temperature $\left(21 \pm 2{ }^{\circ} \mathrm{C}\right)$. The prepared diets were fed to Nile tilapia for 30 days with or without deltamethrin (DMT) ambient exposure $(15 \mu \mathrm{g} / \mathrm{L})$. The groups were named control (basal diet without DMT toxicity), DMT (basal diet with DMT toxicity), synbiotic (synbiotics without DMT toxicity), and DMT + synbiotic (synbiotics with DMT toxicity). The results displayed upregulated transcription of catalase, glutathione peroxidase, and interferon (IFN- $\gamma$ ) genes caused by DMT exposure and synbiotic feeding when compared with the controls. Moreover, HSP70 and CASP3 genes displayed increased transcription caused by DMT exposure without synbiotic feeding. However, fish fed with synbiotics 
showed downregulated HSP70 and CASP3 gene expressions. The transcription of IL-1 $\beta$ and IL-8 genes were also decreased by DMT exposure, while fish fed synbiotics showed upregulated levels. DMT exposure resulted in irregular histopathological features in gills, intestine, spleen, and liver tissues, while fish fed synbiotics showed regular, normal, and protected histopathological images. Our results indicated that dietary synbiotics ameliorated histopathological damages in DMT-exposed tilapia through alleviation of oxidative stress and inflammation as well as enhancing the immunity.

Keywords: deltamethrin; synbiotic; Nile tilapia; histopathology; inflammation; suboptimal temperature

\section{Introduction}

Aquatic pollutants constitute a significant problem that threatens the basic requirements for aquaculture-derived food [1]. The shortage of water resources has forced fish farmers to reuse agricultural drainage water, which might contain pesticides and insecticides [2]. The continuous exposure to toxic derivatives results in oxidative stress, thereby causing immunosuppression and a high possibility of infection attacks [3,4]. Several studies clarified the negative impact of pesticides and insecticides on the production of finfish species and their health status. Traditionally, deltamethrin (DMT) is applied as a model pesticide in the agriculture sector, and it can be present in refluxed agricultural drainage water, leading to harmful impacts on the ecological system [5]. High levels of DMT derivatives induce oxidative stress and systemic and mucosal inflammation in finfish species [6]. In this regard, the immune cells and functional cells lose their function to protect fish from stressors and infection $[7,8]$.

The identification of environmentally friendly alternative substances that can reduce the usage of antibiotics in aquaculture is highly recommended [9-11]. Natural functional supplements are substantial factors with high potential to enhance aquatic organisms' antioxidative and immune responses [12,13]. Probiotics, prebiotics, their mixture, i.e., "synbiotics", and natural feed ingredients such as insect meal have been shown to be applicable supplements in aquafeed with immunostimulant ability [14-16]. Indeed, synbiotics boast the combined effects of both pro- and prebiotic supplements, beginning from the activation of the local intestinal immunity and the related entire body immunity [17]. Many studies investigated the effects of synbiotics as functional growth enhancers, immunostimulant agents $[18,19]$, and antioxidative factors [20,21]. Moreover, synbiotics were validated as anti-inflammatory agents with a high capacity to decrease the impact of stressors $[22,23]$ on the performance of finfish species [14]. Heat-killed beneficial bacterial cells, "paraprobiotics", are a new form of probiotics and were introduced to the aquafeed industry, as they can potentiate aquatic animals' growth performance, immunity, and well-being [24,25]. In this context, dietary-inactivated Lactobacillus plantarum L-137 cells (LP20) were successfully included in aquafeed and resulted in improved growth behavior, digestibility, and health conditions for several aquatic animals [26-28]. Yeast cell-derived substances, such as $\beta$-glucan, were also demonstrated as functional immunostimulants when included in aquafeed [29]. The mixture of LP20 and $\beta$-glucan was investigated in several studies and approved as an active immunobiotic in aquaculture [30-33]. In our previous study, a dietary mixture of LP20 and $\beta$-glucan enhanced the growth performance, hematobiochemical indices, and immune response of Nile tilapia. Concurrently, Nile tilapia treated with a mixture of LP20 and $\beta$-glucan displayed high resistance against DMT toxicity [30]. Nevertheless, the present study tested the influence of the dietary LP20 and $\beta$-glucan mixture on the histopathological features, antioxidant status, and anti-inflammation induced by DMT in Nile tilapia.

Nile tilapia is known globally as a feasible commercial fish species with high tolerance to environmental stressors [34]. The optimal growth performance of Nile tilapia requires a stable water temperature between 26 and $28^{\circ} \mathrm{C}$, while higher temperatures and suboptimal water temperature affect the regular performance of the fish [35]. In Egypt, the water 
temperature decreases below the optimal level during wintertime. Under low-temperature conditions, fish suffer from low feed consumption due to their reduced metabolism [36]. The toxic impacts of pesticides and insecticides are strongly correlated with water temperature, as it can increase or decrease the efficacy of toxins and their influence on aquatic organisms [37]. In this regard, Dawood et al. [30] reported that dietary synbiotics alleviated the negative impacts on the growth performance, blood health, and immune response of Nile tilapia. In our previous study, we examined the impact of DMT toxicity on the growth performance indices of Nile tilapia fed dietary synbiotics [30]. Herein, this research aimed to evaluate the protective effects of synbiotic inclusion on the transcription of immune genes, antioxidant capacity, and pro-inflammatory cytokine levels in the liver as well as histopathological impacts related to inflammation of Nile tilapia under DMT exposure.

\section{Materials and Methods}

\subsection{Fish, Diets, and Experimental Design}

Two sets of diets were formulated by supplementing the basal diet with 0 or $550 \mathrm{mg}$ synbiotic $/ \mathrm{kg}$ (500 g $\beta$-glucan Daigon do, Tokyo, Japan $+50 \mathrm{mg}$ of heat killed Lactobacillus plantarum, $2 \times 10^{11}$ CFU per g (LP20), House Wellness Foods Corp., Itami, Japan) [38]. The formulation of the basal diet was previously described by Gewaily et al. [39] and Dawood et al. [40]. To prepare the test diets, fish meal, soybean meal, wheat bran, yellow corn, gluten, starch, dicalcium phosphate, vitamin, and mineral mixture ingredients were mixed; then, $30-40 \%$ water was added. The synbiotic mixture $(550 \mathrm{mg} / \mathrm{kg}$ diet) was mixed with fish oil and added to the basal diet ingredients. All ingredients, synbiotic additives, fish oil, and water were mixed and pelleted using a meat mincer to produce a dough with a 1 to $2 \mathrm{~mm}$ die. Prepared pellets were air dried for $24 \mathrm{~h}$ and stored in a dry place. The formulated diets were analyzed using the standard method [41]. Table 1 shows the formulation and nutrient composition of the test diets. The prepared diets were fed to Nile tilapia with or without DMT ambient exposure $(15 \mu \mathrm{g} / \mathrm{L})(98.5 \%$, Kafr El-Zayat Company for Chemicals and Pesticides, El-Gharbeya, Egypt) for 30 days. The doses of the synbiotic mixture and DMT were proposed by following the methods of Dawood et al. [30] and Cengiz et al. [42], respectively.

Table 1. Basal diet formulation and chemical composition.

\begin{tabular}{cccc}
\hline Ingredient & $(\mathbf{\%})$ & Composition & $\mathbf{( \% )}$ \\
\hline Fish meal & 8 & Dry matter & 90.66 \\
Soybean meal & 42 & Crude protein & 30.05 \\
Wheat bran & 10 & Ether extract & 6.22 \\
Yellow corn & 20 & Crude fibers & 4.95 \\
Gluten & 6 & Total ash & 3.95 \\
Fish oil & 3 & Gross energy $(\mathrm{KJ} / \mathrm{g})^{*}$ & 18.98 \\
Dicalcium phosphate & 1 & & \\
Vitamin and mineral mixture & 2 & & \\
Vitamin C & 0.08 & & \\
Starch & 7.92 & & \\
* Gross energy was calculated based on the values for protein, lipid, and carbohydrate as 23.6, 39.5, and $_{17.2 \mathrm{~kJ} / \mathrm{g} \text {, respectively. }}$
\end{tabular}

Fish were collected from a local farm and transferred to Sakha Aquaculture Research Unit, Kafrelsheikh, Egypt. After acclimatization for 1 week (with basal diet), Nile tilapia $(28.21 \pm 1.34 \mathrm{~g})$ were randomly allocated to 12 glass aquaria $(60 \mathrm{~L})$. Each experimental aquarium was provided with a continuous electric aerator, and half of the water in each tank was exchanged daily with freshly dechlorinated water. Then, fish were allocated to four groups (triplicates) with 10 fish in each replicate, where they were fed the basal diet or synbiotics (550 mg/ $\mathrm{kg}$ basal diet) and kept at a suboptimal water temperature $\left(21 \pm 2{ }^{\circ} \mathrm{C}\right)$. The prepared diets were fed to Nile tilapia with or without DMT ambient exposure $(15 \mu \mathrm{g} / \mathrm{L})$. Fish were fed the test diets by hand for 30 days twice daily (08:00 and 
15:00) at $3 \%$ of the bodyweight. The groups were named control (basal diet without DMT toxicity), DMT (basal diet with DMT toxicity), synbiotic (synbiotic without DMT toxicity), and DMT + synbiotic (synbiotic with DMT toxicity) (Figure 1).

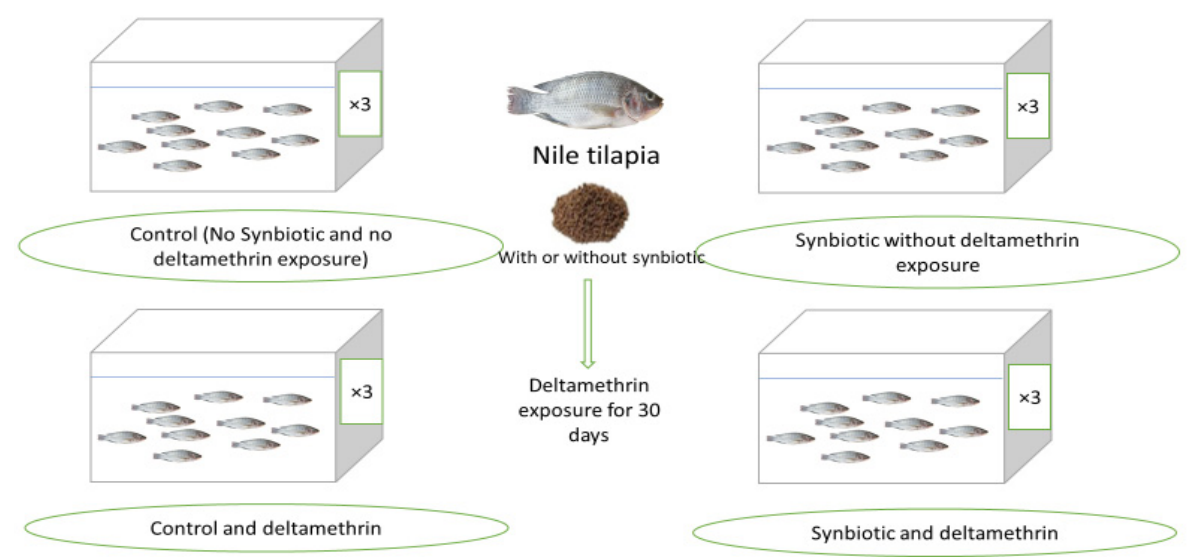

Figure 1. Schematic summary of the study protocol.

DMT was added to the aquaria daily to keep the final concentration fixed at $15 \mu \mathrm{g}$ DMT/L. Fish were fed with test diets up to the satiation level 2 times (08:00 and 16:00) daily. The farming environment was under a natural day and night cycle (12:12 h). The water quality in each aquarium was checked weekly and reported. The water temperature was $21 \pm 2{ }^{\circ} \mathrm{C}$, with $\mathrm{pH} 7.1 \pm 0.8$, dissolved oxygen $6.5 \pm 0.5 \mathrm{mg} / \mathrm{L}$, and total ammonia $0.23 \pm 0.03 \mathrm{mg} / \mathrm{L}$.

\subsection{Histopathology Study}

The histopathological study was carried out by following the method of Gewaily et al. [39], where three fish per aquarium $(\mathrm{N}=9)$ were collected, and their viscera were dissected. Then, the intestines, livers, spleens, and gills were separated and fixed in Bouin's solution for 18-24 h. The tissues were dehydrated using alcohol, cleared in xylene, and embedded in paraffin wax [43]. Then, $5 \mu \mathrm{m}$ thick sections were obtained with a rotatory microtome (RM 20352035; Leica Microsystems, Wetzlar, Germany) and stained with hematoxylin and eosin stain. Finally, the stained tissue sections were viewed and imaged with a digital camera connected to a BX50/BXFLA microscope (Olympus, Tokyo, Japan).

\subsection{Transcriptome Assay}

Three fish from each aquarium $(\mathrm{N}=9)$ were selected for liver dissection at the end of the trial and frozen at $-80{ }^{\circ} \mathrm{C}$ for RNA extraction. Fifty milligrams of the liver was used to extract RNA using Trizol (iNtRON Biotechnology, Inc., Gyeonggi-do, Korea) following the manufacturer's guidelines. The quantity and quality of RNA were checked with a NanoDrop (UV-Vis spectrophotometer Q5000/ Quawell, San Jose, CA, USA). The preparation of $\mathrm{CDNA}$ was carried out using a SensiFAST ${ }^{\mathrm{TM}} \mathrm{CDNA}$ synthesis kit (Bioline, London, UK) following the manufacturer's guidelines. The primers of heat shock protein 70 (HSP70) [44], caspase-3 (CASP3) [45], catalase (CAT) [46], glutathione peroxidase (GPx) [47], interleukin $1 \beta$ (IL-1 $\beta$ ) [48], interleukin 8 (IL-8) [49], and interferon-gamma (IFN- $\gamma$ ) [48] genes were designed by following the method of Gewaily et al. [39]. Real-time PCR (Stratagene MX3000P) was applied for gene expression using the SYBR Green method (Sensi-Fast SYBR Lo-Rox kit, Bioline, London, UK. The mixture contained $20 \mu \mathrm{L}$ of $10 \mu \mathrm{L}$ SYBR mastermix $+0.5 \mu \mathrm{M}$ of each primer $+2 \mu \mathrm{L}$ cDNA. The reaction conditions were $10 \mathrm{~min}$ at $95^{\circ} \mathrm{C}$, followed by 40 cycles of $15 \mathrm{~s}$ at $95^{\circ} \mathrm{C}, 30 \mathrm{~min}$ at $60{ }^{\circ} \mathrm{C}$, and finally $5 \mathrm{~min}$ at $85^{\circ} \mathrm{C}$ (except IFN- $\gamma$, which was at $61^{\circ} \mathrm{C}$ ) for $1 \mathrm{~min}$. For each mRNA, gene expression was corrected by the $\beta$-actin content as a housekeeping gene [49]. The gene expression data were calculated by following the method of Livak and Schmittgen [50]. 


\subsection{Statistical Analysis}

Levene's test examined variance homogeneity of data to confirm the normality and homogeneity of data. If the variance homogeneity threshold could be met, the data were analyzed with Duncan's test. All data were analyzed using one-way analysis of variance (ANOVA) with SPSS 22.0 software (version 22, SPSS Inc., Armonk, NY, USA) and are shown as means \pm standard deviation (SD) at $p<0.05$.

\section{Results}

\subsection{Histopathological Image}

The gills showed congested and large blood vessels in the primary filaments caused by DMT exposure. The apical ends of secondary filaments were dilated, with the erosion of cells in some areas (Figure 2B). However, the gills of the tilapia fed control or synbiotics showed a healthy histological structure (Figure 2A,C,D).

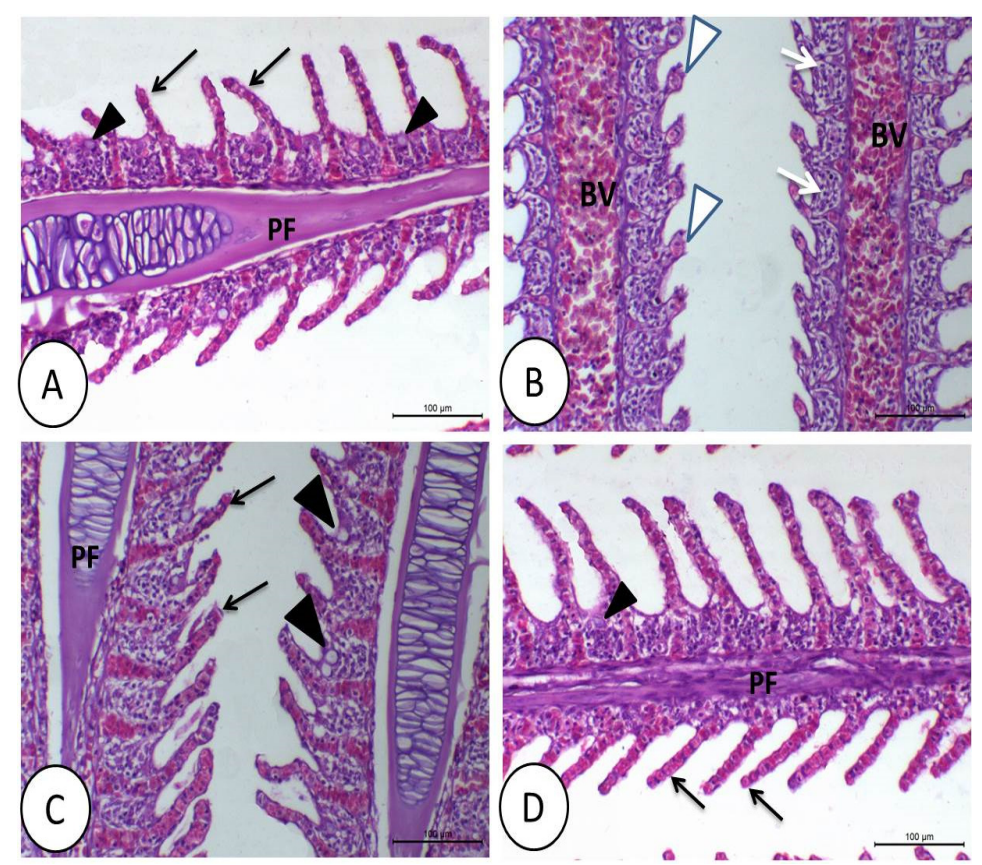

Figure 2. Histology of gills of Nile tilapia in the control (A), deltamethrin (DMT) (B), synbiotic (C), and DMT with synbiotic (D) groups. In (A,C,D), the gills show normal histological structures, including primary filaments (PF), secondary filaments (black arrow), and mucous cells (black arrowhead) between the secondary filaments. The toxic effect of DMT (B) causes telangiectasia and erosion of secondary filaments (white arrowhead), congestion of blood vessels of primary filaments (BV), and degeneration of epithelial lining (white arrow). H\&E staining; bar $=100 \mu \mathrm{m}$.

The intestine of tilapia fed control or symbiotic diets showed a healthy structure (Figure 3A,C). DMT impeded the growth of the intestinal villi, with some collapse and destruction of the cell lining (Figure 3B). However, in fish fed synbiotics only, the intestinal epithelium revealed a very clear, simple columnar epithelium with many goblet cells. The intestinal villi were characterized by increased thickness and height (Figure 3C). However, fish that were fed with synbiotics and exposed to DMT showed not only a normal epithelium but also increased number, width, and height of the villi, as well as many prominent goblet cells (Figure 3D).

The liver of fish fed control or synbiotic diets without DMT exposition appeared normal (Figure $4 \mathrm{~A}, \mathrm{C}$ ). The liver in the DMT group was vacuolated, and most of the hepatocytes showed fatty erosion and pyknotic nuclei with congested and dilated blood sinusoids (Figure 4B). By feeding synbiotics, the liver retained its normal structure in fish exposed to DMT (Figure 4D). 


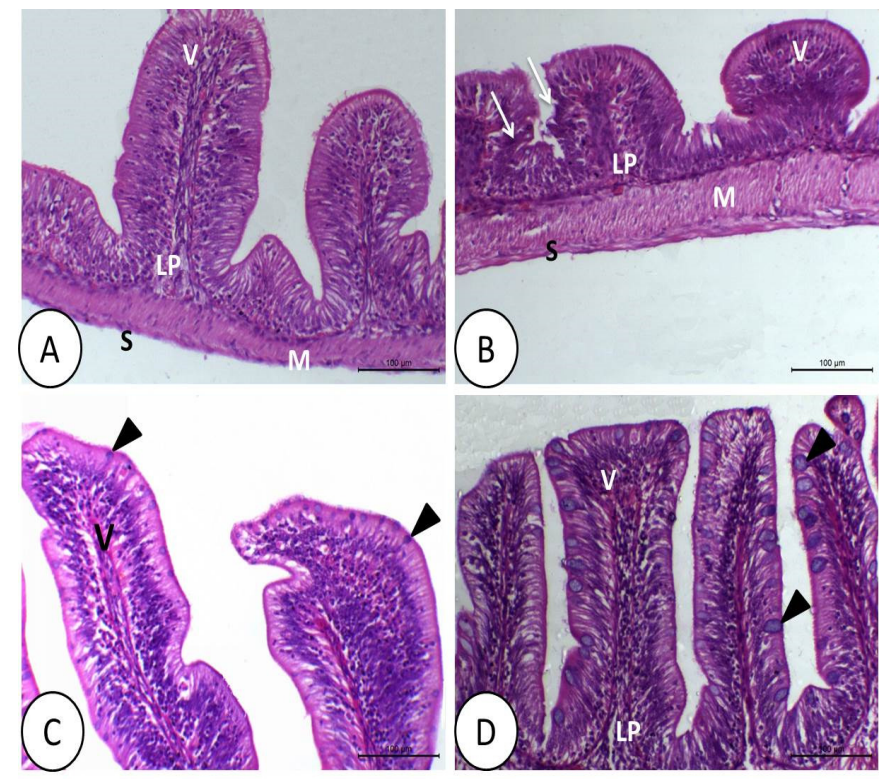

Figure 3. Histology of intestine of Nile tilapia in the control (A), deltamethrin (DMT) (B), synbiotic (C), and DMT with synbiotic (D) groups. In (A), the intestine shows normal histological structures, including the intestinal villi (V), lamina propria sub mucosa (LP), tunica muscularis (M), and tunica serosa (S). The toxic effect of deltamethrin (B) decreases the number of intestinal villi with degeneration of the epithelial lining (white arrow) and leukocytic infiltration. In (C,D), the intestine has a normal appearance like that in the control group. The intestinal villi increase in number, height, and width with prominent goblet cells (black arrowhead) and without a toxic effect of deltamethrin in group (D). H\&E staining; bar $=100 \mu \mathrm{m}$.

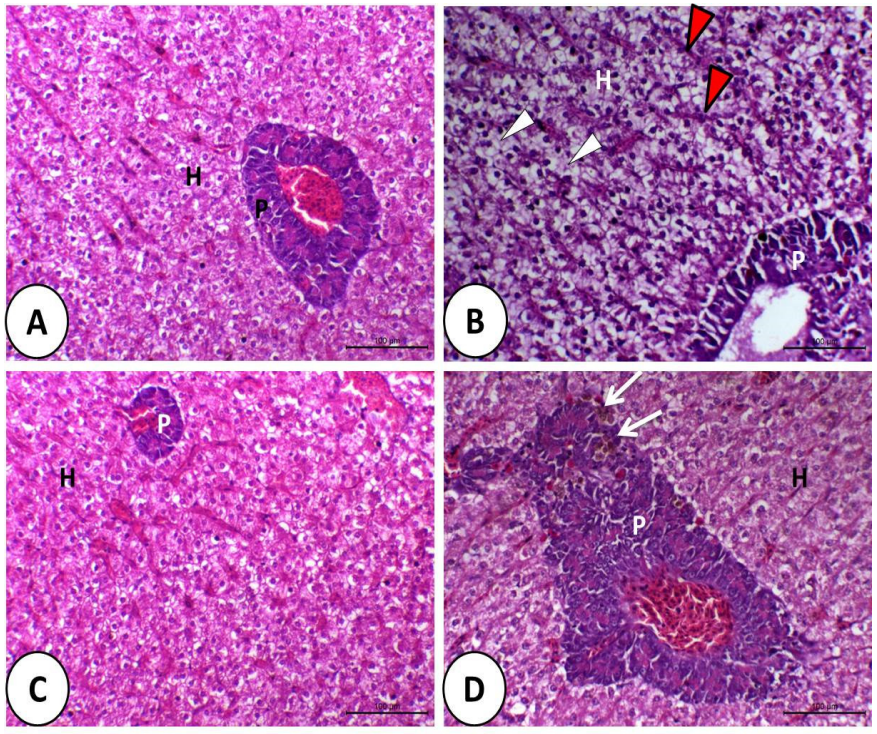

Figure 4. Histology of liver of Nile tilapia in the control (A), deltamethrin (DMT) (B), synbiotic (C), and DMT with synbiotic (D) groups. In A and C, the hepatopancreas consists of polyhedral hepatocyte $(\mathrm{H})$ and pancreatic cells $(\mathrm{P})$. The toxic effect of deltamethrin $(\mathbf{B})$ causes fatty degeneration (white arrowhead) of hepatocytes and congestion of blood sinusoids (red arrowhead). In (D), the hepatopancreas has a relatively normal structure in addition to some melanomacrophages (white arrow), especially in the pancreatic part (P). H\&E staining; bar $=100 \mu \mathrm{m}$.

The control and synbiotic groups showed a normal structure of the spleen (Figure 5A,C). However, in the DMT group, there was a large area of necrosis with decreased white bulbs 
compared with the control and synbiotic groups (Figure 5B). There was no sign of necrosis in the spleen in fish fed synbiotics and exposed to DMT. Moreover, melanomacrophages were aggregated around the blood vessels of the splenic tissue (Figure 5D).
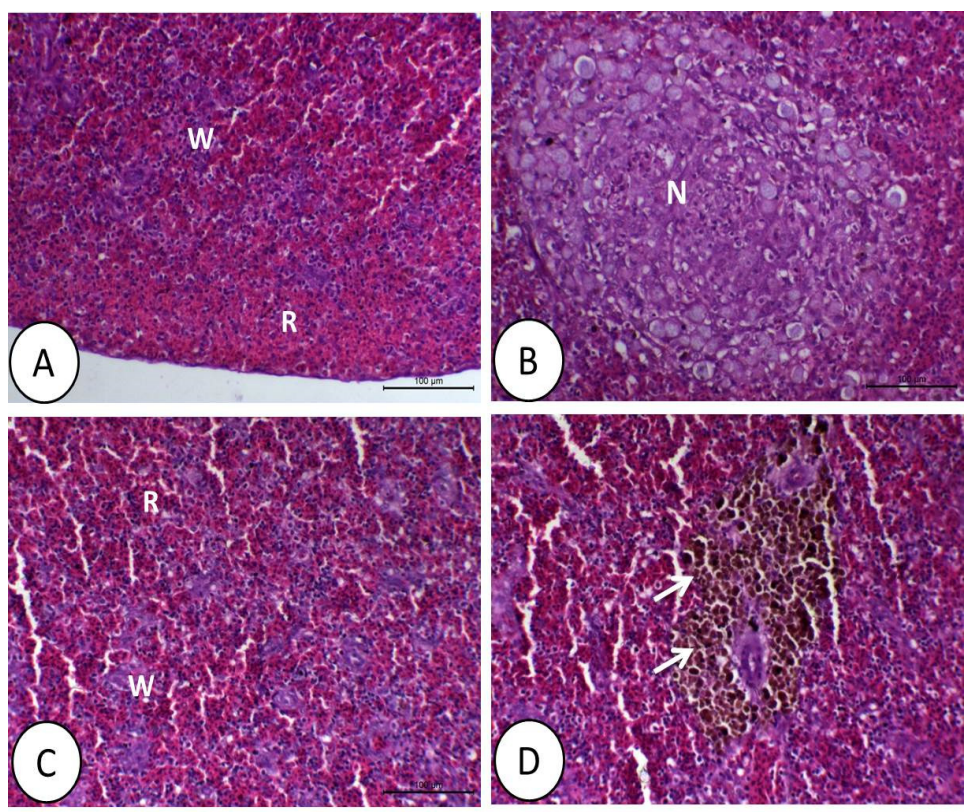

Figure 5. Histology of spleen of Nile tilapia in the control (A), deltamethrin (DMT) (B), synbiotic (C), and both DMT with synbiotic (D) groups. In A and C, the spleen consists of white (W) and red pulps $(\mathrm{R})$ that increase in group $(\mathrm{C})$. In the deltamethrin group (B), the splenic tissue reveals a large area of necrosis $(\mathrm{N})$. In (D), the splenic tissue has a relatively normal structure with increased melanomacrophages (white arrow). H\&E staining; bar $=100 \mu \mathrm{m}$.

\subsection{Gene Transcription}

Fish fed synbiotics and exposed to DMT displayed increased transcription of CAT and GPx genes $(p<0.05$; Figure $6 \mathrm{~A}, \mathrm{~B})$. A similar trend was observed in fish fed synbiotics without DMT exposure $(p<0.05)$.

(A)

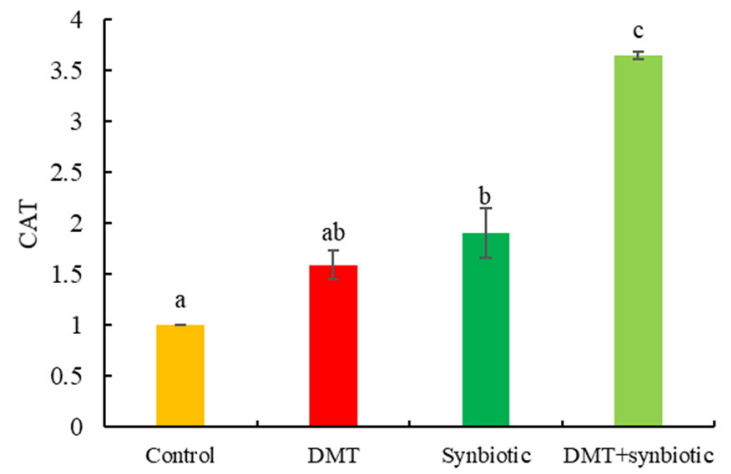

(B)

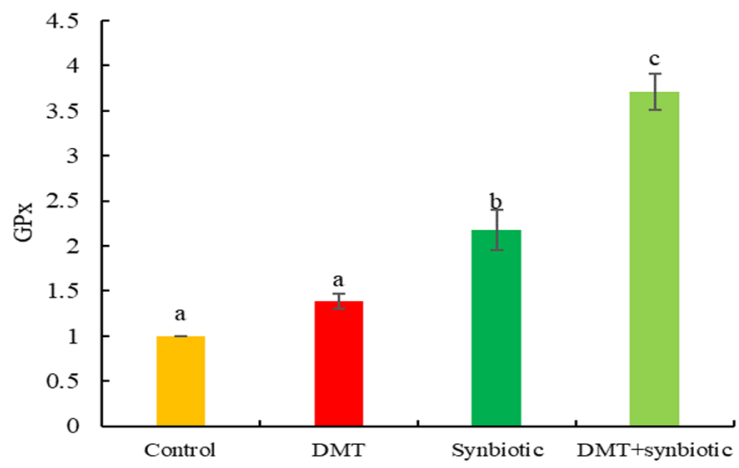

Figure 6. Transcription of antioxidative genes: (A) catalase (CAT) and (B) glutathione peroxidase (GPx) in Nile tilapia treated with deltamethrin (DMT) with synbiotic feeding. Bars represent mean $\pm \mathrm{SD}(\mathrm{n}=3)$, and different letters show significant differences $(p<0.05)$.

HSP70 and CASP3 genes exhibited increased transcription in fish exposed to DMT in the absence of synbiotic feeding ( $p<0.05$; Figure 7A,B). 
(A)

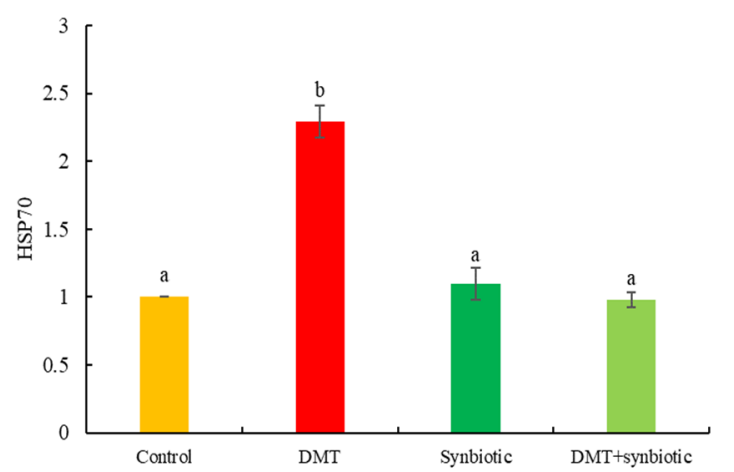

(B)

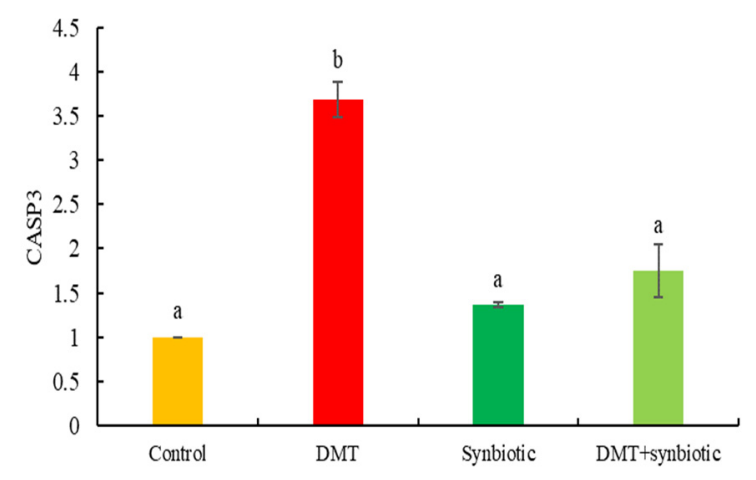

Figure 7. Transcription of (A) heat shock protein 70 (HSP70) and (B) caspase 3 (CASP3) in Nile tilapia treated with deltamethrin (DMT) with synbiotic feeding. Bars represent mean $\pm \mathrm{SD}(\mathrm{n}=3)$, and different letters show significant differences $(p<0.05)$.

IL-1 $\beta$ was downregulated in tilapia with DMT exposure and upregulated by synbiotic and DMT + synbiotic $(p<0.05$; Figure 8 A). However, compared to the control, IFN- $\gamma$ displayed significantly increased transcription when fish were exposed to DMT and fed synbiotic (DMT + synbiotic) $(p<0.05$; Figure 8 B). DMT resulted in lower IL-8 transcription than that in the other groups ( $p<0.05$; Figure 8 C). Fish fed synbiotics and exposed to DMT (DMT + synbiotic) showed more IL-8 upregulation than that in the other groups $(p<0.05)$. Notably, fish exposed to DMT without symbiotic feeding showed the lowest expression of IL-8 $(p<0.05)$.

(A)

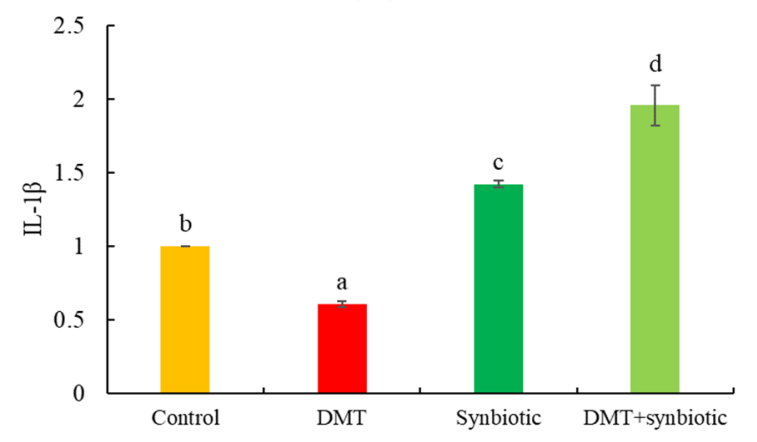

(B)

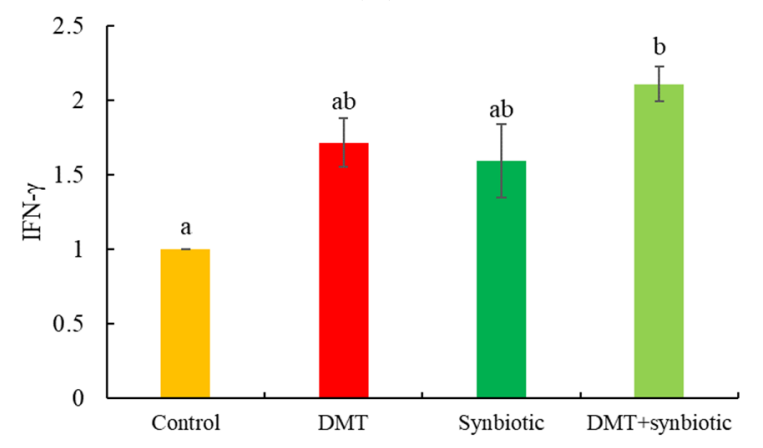

(C)

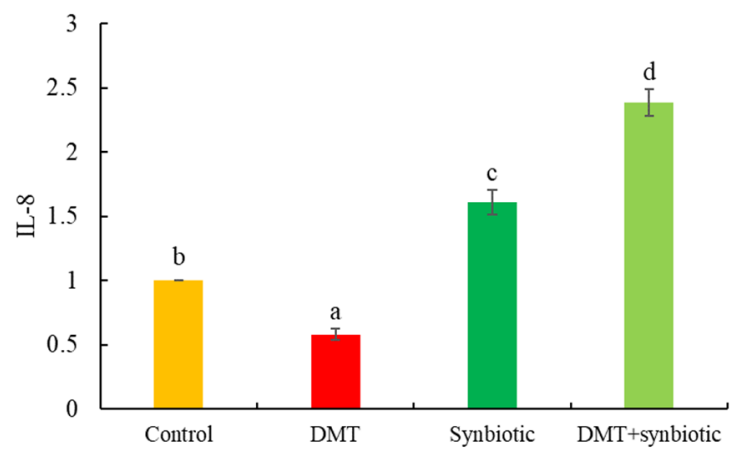

Figure 8. Transcription of (A) interleukin $1 \beta$ (IL-1 $\beta$ ), (B) interferon-gamma (IFN- $\gamma$ ), (C) interleukin 8 (IL-8) in Nile tilapia treated with deltamethrin (DMT) with synbiotic feeding. Bars represent mean \pm SD $(n=3)$, and different letters show significant differences $(p<0.05)$. 


\section{Discussion}

The ecosystem comprises numerous environmental stressors involved in various biological responses [51,52]. High water temperature usually leads to high absorption rates of pesticides compared to low temperatures [53]. However, continuous exposure to pesticides can also harm aquatic organisms' performance and health, regardless of the water temperature $[54,55]$. The current trial was conducted under a suboptimal water temperature $\left(21 \pm 2{ }^{\circ} \mathrm{C}\right)$. Normally, Nile tilapia can consume food and grow well under temperatures ranging between 25 and $28^{\circ} \mathrm{C}$ [35], but low temperature weakens the growth and activity of fish [56]. In this sense, the accumulation of DMT in the rearing water of Nile tilapia suffering from abnormal feeding habits may lead to suppressed immune and antioxidative responses resulting from inflammation in different body tissues. It has been reported that ambient DMT exposure can harm aquatic animals through impairing the physiological, immunological, and pro-inflammatory responses [11], which has been further confirmed in the present study. Synbiotic application is one of the most effective tools that has been recently reported in aquafeed $[18,19]$. Synbiotics are a mixture of probiotics and prebiotics, and they can effectively accelerate the resistance of fish against stress through the role of prebiotics in providing the beneficial bacteria (probiotics) with the energy and nutrients, thereby demonstrating their immunomodulation effects [57]. Furthermore, prebiotics themselves have immunomodulation and antioxidative roles [58]. Thus, it has been hypothesized that including synbiotics in tilapia diets may relieve the severe impacts of DMT exposure in rearing water.

The combined exposure to multiple stressors causes DNA damage during cell division [37]. Concurrently, the histological features of gills, intestines, livers, and spleens of tilapia are expected to deteriorate and lead to histopathological inflammation that suppresses immunity and antioxidative conditions [59]. Furthermore, the multiple stressors induce oxidative stress and allow the generation of free radicals, which damage the DNA and tissues [51]. However, synbiotic feeding helps in protecting fish intestines, spleens, and liver tissues from DMT-induced stress.

Tumor necrosis factor- $\alpha$ (TNF- $\alpha$ ) and interleukin 8 (IL-8) are pro-inflammatory molecules functioning as inflammation regulation factors [60]. The overproduction of reactive oxygen metabolites (ROS) is the leading cause of oxidative stress, resulting in loss of cell function [61]. High ROS levels break down the lipids, causing lipid peroxidation that can induce cellular oxidative damage [62]. Under high oxidative damage, cells secrete antioxidative enzymes to degenerate the overproduced ROS and maintain the antioxidation balance [63]. Similarly, in the current study, we observed that DMT exposure decreased CAT and GPx gene transcription, while synbiotic feeding increased CAT and GPx gene expressions. Synbiotics as feed additives have been widely used in several fish species [20,21]. Interestingly, high antioxidation capacity against DMT toxicity is probably related to synbiotics as a functional antioxidation agent.

In the present study, the inclusion of synbiotics in the diet of tilapia increased their tolerance to DMT toxicity by increasing the antioxidative and anti-inflammatory responses due to the presence of peptidoglycan and lipopolysaccharides [4,64,65]. El-Murr et al. [4] and Dawood et al. [6] assumed that using $\beta$-glucan or L. plantarum markedly led to high antioxidation and immunity to cope with the impacts of fipronil or DMT in Nile tilapia. More recently, Nile tilapia fed probiotics, prebiotics, and synbiotics displayed enhanced hemato-immunological responses under DMT toxicity [30]; however, the present study presents a deep interpretation via transcriptomic and histopathological tools.

The upregulation of IFN- $\gamma$, IL- 8 , and IL- $1 \beta$ genes suggested increased resistance against stressors. In this sense, the results confirmed the protective role of synbiotics against inflammation and immunosuppression induced by DMT and low temperature via activating the IFN- $\gamma$, IL-8, and IL- $1 \beta$ factors. Synbiotics are speculated as functional additives with the ability to stimulate $\mathrm{T}$ lymphocytes $[4,64,65]$.

The environmental stressors are the main reason for the high expression of HSP70 involved in alleviating apoptosis in the cells [66-68]. The results showed upregulated 
HSP70 in fish exposed to DMT toxicity, but dietary synbiotics lowered HSP70 expression. The results illustrated that the tested synbiotic is associated with antistress efficacy in fish.

CASP3 is also involved in apoptosis and is responsible for cellular DNA fragmentation during stress $[45,69]$. The results showed upregulated CASP3 in fish with DMT-induced stress but downregulation in the case of dietary synbiotics, indicating the protective role of synbiotics against DMT-induced apoptosis in Nile tilapia.

The above results clearly show the depressed immunity, antioxidative, and antiinflammatory responses of Nile tilapia exposed to DMT toxicity under a suboptimal water temperature. However, the dietary synbiotic mixture alleviated the inflammation and oxidative stress induced by DMT and low water temperature. The exact mode of action of synbiotic efficacy can be explained by its immunomodulation activity [70,71], which enhances the local intestinal immunity and protects intestinal barriers from the expected toxicity induced by DMT in the rearing water. More specifically, signals related to immunity show correlations between the local intestinal immunity and the innate immune cells in the fish body [72]. Beneficial microbial cells and glucans can also be easily accessed through specific receptors on the immune cells to enhance cell immunity [73]. The enhanced antioxidative status can be attributed to the synbiotics' role in activating immunity under the current trial conditions. Additionally, it is suggested that the synbiotic mixture could increase the feed intake of fish regardless of the low water temperature, which would lead to more available nutrients required to enhance the metabolic functions related to deterioration induced by DMT in the different body organs. In this regard, synbiotics are known for their growth-promoting and metabolic regulation activities, as described previously in several studies $[74,75]$. Thus, it is recommended that future studies reveal the potential roles of synbiotics in the feed utilization of finfish species reared at suboptimal water temperatures.

\section{Conclusions}

In conclusion, including synbiotics in the diet of Nile tilapia stimulates the immunity and antioxidant system in the fish, which enables the fish reared at a suboptimal temperature to counteract the immunity suppression and oxidative stress caused by DMT exposure. Furthermore, fish fed synbiotics showed regular, healthy, and protected histopathological images.

Author Contributions: Conceptualization, M.S.G., S.E.A., E.M.M., M.F.A.-k., I.M.A.E.-R., M.E.-S., M.A., S.H.A.R. and M.A.O.D.; Data curation, M.S.G., S.E.A. and M.A.O.D.; Formal analysis, M.S.G. and S.E.A.; Funding acquisition, M.E.-S., M.A., H.V.D., and M.A.O.D.; Investigation, M.F.A.-k., M.E.-S. and M.A.O.D.; Methodology, M.F.A.-k.; Project administration, M.A.O.D.; Resources, E.M.M. and M.A.O.D.; Validation, M.A. and M.A.O.D.; Writing-Original draft, M.S.G., I.M.A.E.-R., M.A., S.H.A.R., M.F.E.B. and M.A.O.D.; Writing-Review and editing, H.V.D. and M.A.O.D. All authors have read and agreed to the published version of the manuscript.

Funding: This work was carried out using the facilities and materials of Taif University Researchers Supporting Project, number TURSP-2020/57, Taif University, Taif, Saudi Arabia. This research work was partially supported by Chiang Mai University.

Institutional Review Board Statement: The experiments were performed according to the guidelines of a local ethics committee (Number 11/2020 EC) at the faculty of Agriculture, Kafrelsheikh University, Kafrelsheikh, Egypt.

Informed Consent Statement: Not applicable.

Data Availability Statement: The datasets generated during and/or analysed during the current study are available from the corresponding author on reasonable request.

Acknowledgments: The authors extend their appreciation to Taif University for funding current work by Taif University Researchers Supporting Project number (TURSP-2020-57), Taif University, Taif, Saudi Arabia. This research work was partially supported by Chiang Mai University.

Conflicts of Interest: The authors declare no conflict of interest. 


\section{References}

1. Ahmadifar, E.; Dawood, M.A.O.; Moghadam, M.S.; Sheikhzadeh, N.; Hoseinifar, S.H.; Musthafa, M.S. Modulation of immune parameters and antioxidant defense in zebrafish (Danio rerio) using dietary apple cider vinegar. Aquaculture 2019, $513,734412$. [CrossRef]

2. $\quad$ El Megid, A.A.; Al Fatah, M.E.A.; El Asely, A.; El Senosi, Y.; Moustafa, M.M.A.; Dawood, M.A.O. Impact of pyrethroids and organochlorine pesticides residue on IGF-1 and CYP1A genes expression and muscle protein patterns of cultured Mugil capito. Ecotoxicol. Environ. Saf. 2020, 188, 109876. [CrossRef] [PubMed]

3. Soliman, N.F.; Yacout, D.M.M. Aquaculture in Egypt: Status, constraints and potentials. Aquac. Int. 2016, $24,1201-1227$. [CrossRef]

4. El-Murr, A.E.I.; El Hakim, Y.A.; Neamat-Allah, A.N.F.; Baeshen, M.; Ali, H.A. Immune-protective, antioxidant and relative genes expression impacts of $\beta$-glucan against fipronil toxicity in Nile tilapia, Oreochromis niloticus. Fish Shellfish. Immunol. 2019, 94, 427-433. [CrossRef] [PubMed]

5. Suvetha, L.; Saravanan, M.; Hur, J.-H.; Ramesh, M.; Krishnapriya, K. Acute and sublethal intoxication of deltamethrin in an Indian major carp, Labeo rohita: Hormonal and enzymological responses. J. Basic Appl. Zool. 2015, 72, 58-65. [CrossRef]

6. Dawood, M.A.O.; Moustafa, E.M.; Gewaily, M.S.; Abdo, S.E.; AbdEl-Kader, M.F.; SaadAllah, M.S.; Hamouda, A.H. Ameliorative effects of Lactobacillus plantarum L-137 on Nile tilapia (Oreochromis niloticus) exposed to deltamethrin toxicity in rearing water. Aquat. Toxicol. 2020, 219, 105377. [CrossRef]

7. Datta, M.; Kaviraj, A. Ascorbic acid supplementation of diet for reduction of deltamethrin induced stress in freshwater catfish Clarias gariepinus. Chemosphere 2003, 53, 883-888. [CrossRef]

8. Fanta, E.; Rios, F.S.A.; Romão, S.; Vianna, A.C.C.; Freiberger, S. Histopathology of the fish Corydoras paleatus contaminated with sublethal levels of organophosphorus in water and food. Ecotoxicol. Environ. Saf. 2003, 54, 119-130. [CrossRef]

9. Bennour, E.E.G.; Timoumi, R.; Annaibi, E.; Mokni, M.; Omezzine, A.; Bacha, H.; Abid-Essefi, S. Protective effects of kefir against deltamethrin-induced hepatotoxicity in rats. Environ. Sci. Pollut. Res. 2019, 26, 18856-18865. [CrossRef]

10. Jindal, R.; Sinha, R.; Brar, P. Evaluating the protective efficacy of Silybum marianum against deltamethrin induced hepatotoxicity in piscine model. Environ. Toxicol. Pharmacol. 2019, 66, 62-68. [CrossRef]

11. Dawood, M.A.O.; Abdo, S.E.; Gewaily, M.S.; Moustafa, E.M.; SaadAllah, M.S.; AbdEl-Kader, M.F.; Hamouda, A.H.; Omar, A.A.; Alwakeel, R.A. The influence of dietary $\beta$-glucan on immune, transcriptomic, inflammatory and histopathology disorders caused by deltamethrin toxicity in Nile tilapia (Oreochromis niloticus). Fish Shellfish. Immunol. 2020, 98, 301-311. [CrossRef]

12. Srichaiyo, N.; Tongsiri, S.; Hoseinifar, S.H.; Dawood, M.A.O.; Esteban, M.Á.; Ringø, E.; Van Doan, H. The effect of fishwort (Houttuynia cordata) on skin mucosal, serum immunities, and growth performance of Nile tilapia. Fish Shellfish. Immunol. 2020, 98, 193-200. [CrossRef]

13. Moustafa, E.M.; Dawood, M.A.O.; Assar, D.H.; Omar, A.A.; Elbialy, Z.I.; Farrag, F.A.; Shukry, M.; Zayed, M.M. Modulatory effects of fenugreek seeds powder on the histopathology, oxidative status, and immune related gene expression in Nile tilapia (Oreochromis niloticus) infected with Aeromonas hydrophila. Aquaculture 2019, 515, 734589. [CrossRef]

14. Dawood, M.A.O.; Abo-Al-Ela, H.G.; Hasan, M.T. Modulation of transcriptomic profile in aquatic animals: Probiotics, prebiotics and synbiotics scenarios. Fish Shellfish. Immunol. 2020, 97, 268-282. [CrossRef] [PubMed]

15. Maradonna, F.; Gioacchini, G.; Falcinelli, S.; Bertotto, D.; Radaelli, G.; Olivotto, I.; Carnevali, O. Probiotic Supplementation Promotes Calcification in Danio rerio Larvae: A Molecular Study. PLoS ONE 2013, 8, e83155. [CrossRef]

16. Zarantoniello, M.; Bruni, L.; Randazzo, B.; Vargas, A.; Gioacchini, G.; Truzzi, C.; Annibaldi, A.; Riolo, P.; Parisi, G.; Cardinaletti, G.; et al. Partial Dietary Inclusion of Hermetia illucens (Black Soldier Fly) Full-Fat Prepupae in Zebrafish Feed: Biometric, Histological, Biochemical, and Molecular Implications. Zebrafish 2018, 15, 519-532. [CrossRef] [PubMed]

17. Akhter, N.; Wu, B.; Memon, A.M.; Mohsin, M. Probiotics and prebiotics associated with aquaculture: A review. Fish Shellfish Immunol. 2015, 45, 733-741. [CrossRef] [PubMed]

18. Modanloo, M.; Soltanian, S.; Akhlaghi, M.; Hoseinifar, S.H. The effects of single or combined administration of galactooligosaccharide and Pediococcus acidilactici on cutaneous mucus immune parameters, humoral immune responses and immune related genes expression in common carp (Cyprinus carpio) fingerlings. Fish Shellfish. Immunol. 2017, 70, 391-397. [CrossRef]

19. Hasan, M.T.; Jang, W.J.; Tak, J.Y.; Lee, B.-J.; Kim, K.W.; Hur, S.W.; Han, H.-S.; Kim, B.-S.; Min, D.-H.; Kim, S.-K.; et al. Effects of Lactococcuslactis subsp. lactis I2 with Beta-Glucooligosaccharides on Growth, Innate Immunity and Streptococcosis Resistance in Olive Flounder (Paralichthys olivaceus). J. Microbiol. Biotechnol. 2018, 28, 1433-1442. [CrossRef] [PubMed]

20. Cao, H.; Yu, R.; Zhang, Y.; Hu, B.; Jian, S.; Wen, C.; Kajbaf, K.; Kumar, V.; Yang, G. Effects of dietary supplementation with $\beta$-glucan and Bacillus subtilis on growth, fillet quality, immune capacity, and antioxidant status of Pengze crucian carp (Carassius auratus var. Pengze). Aquaculture 2019, 508, 106-112. [CrossRef]

21. Devi, G.; Harikrishnan, R.; Paray, B.A.; Al-Sadoon, M.K.; Hoseinifar, S.H.; Balasundaram, C. Effect of symbiotic supplemented diet on innate-adaptive immune response, cytokine gene regulation and antioxidant property in Labeo rohita against Aeromonas hydrophila. Fish Shellfish. Immunol. 2019, 89, 687-700. [CrossRef]

22. Hoseinifar, S.H.; Ringø, E.; Masouleh, A.S.; Esteban, M.Á. Probiotic, prebiotic and synbiotic supplements in sturgeon aquaculture: A review. Rev. Aquac. 2016, 8, 89-102. [CrossRef]

23. Dawood, M.A.; Koshio, S.; Esteban, M.Á. Beneficial roles of feed additives as immunostimulants in aquaculture: A review. Rev. Aquac. 2018, 10, 950-974. [CrossRef] 
24. Choudhury, T.G.; Kamilya, D. Paraprobiotics: An aquaculture perspective. Rev. Aquac. 2019, 11, 1258-1270. [CrossRef]

25. Singh, S.T.; Kamilya, D.; Kheti, B.; Bordoloi, B.; Parhi, J. Paraprobiotic preparation from Bacillus amyloliquefaciens FPTB16 modulates immune response and immune relevant gene expression in Catla catla (Hamilton, 1822). Fish Shellfish. Immunol. 2017, 66, 35-42. [CrossRef]

26. Van Nguyen, N.; Onoda, S.; van Khanh, T.; Hai, P.D.; Trung, N.T.; Hoang, L.; Koshio, S. Evaluation of dietary Heat-killed Lactobacillus plantarum strain L-137 supplementation on growth performance, immunity and stress resistance of Nile tilapia (Oreochromis niloticus). Aquaculture 2019, 498, 371-379. [CrossRef]

27. Dawood, M.A.; Magouz, F.I.; Salem, M.F.; Abdel-Daim, H.A. Modulation of digestive enzyme activity, blood health, oxidative responses and growth-related gene expression in GIFT by heat-killed Lactobacillus plantarum (L-137). Aquaculture 2019, 505, 127-136. [CrossRef]

28. Yassine, T.; Khalafalla, M.M.; Mamdouh, M.; Elbialy, Z.I.; Salah, A.S.; Ahmedou, A.; Mamoon, A.; El-Shehawi, A.M.; van Doan, H.; Dawood, M.A.O. The enhancement of the growth rate, intestinal health, expression of immune-related genes, and resistance against suboptimal water temperature in common carp (Cyprinus carpio) by dietary paraprobiotics. Aquac. Rep. 2021, $20,100729$. [CrossRef]

29. Leyva-López, N.; Lizárraga-Velázquez, C.E.; Hernández, C.; Sánchez-Gutiérrez, E.Y. Exploitation of Agro-Industrial Waste as Potential Source of Bioactive Compounds for Aquaculture. Foods 2020, 9, 843. [CrossRef] [PubMed]

30. Dawood, M.A.; Abdel-Kader, M.F.; Moustafa, E.M.; Gewaily, M.S.; Abdo, S.E. Growth performance and hemato-immunological responses of Nile tilapia (Oreochromis niloticus) exposed to deltamethrin and fed immunobiotics. Environ. Sci. Pollut. Res. 2020, 27, 1-10. [CrossRef] [PubMed]

31. Dawood, M.A.O.; Magouz, F.I.; Salem, M.F.I.; Elbialy, Z.I.; Abdel-Daim, H.A. Synergetic Effects of Lactobacillus plantarum and $\beta$-Glucan on Digestive Enzyme Activity, Intestinal Morphology, Growth, Fatty Acid, and Glucose-Related Gene Expression of Genetically Improved Farmed Tilapia. Probiotics Antimicrob. Proteins 2019, 12, 389-399. [CrossRef] [PubMed]

32. Dawood, M.A.O.; Moustafa, E.M.; Elbialy, Z.I.; Farrag, F.; Lolo, E.E.E.; Abdel-Daim, H.A.; Abdel-Daim, M.M.; van Doan, H. Lactobacillus plantarum L-137 and/or $\beta$-glucan impacted the histopathological, antioxidant, immune-related genes and resistance of Nile tilapia (Oreochromis niloticus) against Aeromonas hydrophila. Res. Veter. Sci. 2020, 130, 212-221. [CrossRef] [PubMed]

33. Dawood, M.A.O.; Koshio, S.; Ishikawa, M.; Yokoyama, S. Interaction effects of dietary supplementation of heat-killed Lactobacillus plantarum and $\beta$-glucan on growth performance, digestibility and immune response of juvenile red sea bream, Pagrus major. Fish Shellfish. Immunol. 2015, 45, 33-42. [CrossRef]

34. Amin, A.; El Asely, A.; El-Naby, A.S.A.; Samir, F.; El-Ashram, A.; Sudhakaran, R.; Dawood, M.A.O. Growth performance, intestinal histomorphology and growth-related gene expression in response to dietary Ziziphus mauritiana in Nile tilapia (Oreochromis niloticus). Aquaculture 2019, 512, 734301. [CrossRef]

35. El-Sayed, A.-F.M. Tilapia Culture; Academic Press: Cambridge, MA, USA, 2019.

36. Bansemer, M.S.; Forder, R.E.A.; Howarth, G.S.; Suitor, G.M.; Bowyer, J.; Stone, D.A.J. The effect of dietary soybean meal and soy protein concentrate on the intestinal mucus layer and development of subacute enteritis in Yellowtail Kingfish (Seriola lalandi) at suboptimal water temperature. Aquac. Nutr. 2015, 21, 300-310. [CrossRef]

37. Jacquin, L.; Gandar, A.; Aguirre-Smith, M.; Perrault, A.; Le Hénaff, M.; De Jong, L.; Paris-Palacios, S.; Laffaille, P.; Jean, S. High temperature aggravates the effects of pesticides in goldfish. Ecotoxicol. Environ. Saf. 2019, 172, 255-264. [CrossRef]

38. Murosaki, S.; Yamamoto, Y.; Ito, K.; Inokuchi, T.; Kusaka, H.; Ikeda, H.; Yoshikai, Y. Heat-killed Lactobacillus plantarum L-137 suppresses naturally fed antigen-specific IgE production by stimulation of IL-12 production in mice. J. Allergy Clin. Immunol. 1998, 102, 57-64. [CrossRef]

39. Gewaily, M.S.; Shukry, M.; Abdel-Kader, M.F.; Alkafafy, M.; Farrag, F.A.; Moustafa, E.M.; Doan, H.V.; Abd-Elghany, M.F.; Abdelhamid, A.F.; Eltanahy, A.; et al. Dietary Lactobacillus plantarum relieves Nile tilapia (Oreochromis niloticus) juvenile from oxidative stress, immunosuppression, and inflammation induced by deltamethrin and Aeromonas hydrophila. Front. Mar. Sci. 2021, 8. [CrossRef]

40. Dawood, M.A.O.; Eweedah, N.M.; Moustafa, E.M.; Shahin, M.G. Synbiotic efects of Aspergillus oryzae and $\beta$-glucan on growth and oxidative and immune responses of Nile tilapia, Oreochromis niloticus. Probiotics Antimicrob. Proteins 2020, 12, 172-183. [CrossRef]

41. AOAC. Method 2007-04; Association of Official Analytical Chemists: Washington, DC, USA, 2007.

42. Cengiz, E.I.; Bayar, A.S.; Kızmaz, V.; Başhan, M.; Satar, A. Acute Toxicity of Deltamethrin on the Fatty Acid Composition of Phospholipid Classes in Liver and Gill Tissues of Nile tilapia. Int. J. Environ. Res. 2017, 11, 377-385. [CrossRef]

43. Bancroft, J.D.; Gamble, M. Theory and Practice of Histological Techniques; Elsevier Health Sciences: New York, NY, USA, 2008.

44. Hassan, A.; El Nahas, A.; Mahmoud, S.; Barakat, M.; Ammar, A. Thermal stress of ambient temperature modulate expression of stress and immune-related genes and DNA fragmentation in Nile tilapia (Oreochromis niloticus (Linnaeus, 1758)). Appl. Ecol. Environ. Res. 2017, 15, 1343-1354. [CrossRef]

45. Standen, B.T.; Peggs, D.L.; Rawling, M.D.; Foey, A.; Davies, S.J.; Santos, G.A.; Merrifield, D.L. Dietary administration of a commercial mixed-species probiotic improves growth performance and modulates the intestinal immunity of tilapia, Oreochromis niloticus. Fish Shellfish. Immunol. 2016, 49, 427-435. [CrossRef]

46. Goes, E.S.D.R.; Goes, M.D.; de Castro, P.L.; de Lara, J.A.F.; Vital, A.C.P.; Ribeiro, R.P. Imbalance of the redox system and quality of tilapia fillets subjected to pre-slaughter stress. PLoS ONE 2019, 14, e0210742. [CrossRef] [PubMed] 
47. Afifi, M.; Saddick, S.; Abu Zinada, O.A. Toxicity of silver nanoparticles on the brain of Oreochromis niloticus and Tilapia zillii. Saudi J. Biol. Sci. 2016, 23, 754-760. [CrossRef] [PubMed]

48. Qiang, J.; He, J.; Yang, H.; Xu, P.; Habte-Tsion, H.M.; Ma, X.Y.; Zhu, Z.X. The changes in cortisol and expression of immune genes of GIFT tilapia Oreochromis niloticus (L.) at different rearing densities under Streptococcus iniae infection. Aquac. Int. 2016, 24, 1365-1378. [CrossRef]

49. Abo-Al-Ela, H.G.; El-Nahas, A.F.; Mahmoud, S.; Ibrahim, E.M. Vitamin C Modulates the Immunotoxic Effect of $17 \alpha-$ Methyltestosterone in Nile Tilapia. Biochemistry 2017, 56, 2042-2050. [CrossRef] [PubMed]

50. Livak, K.J.; Schmittgen, T.D. Analysis of Relative Gene Expression Data Using Real-Time Quantitative PCR and the $2^{-\Delta \Delta C T}$ Method. Methods 2001, 25, 402-408. [CrossRef]

51. Stara, A.; Zuskova, E.; Vesely, L.; Kouba, A.; Velisek, J. Single and combined effects of thiacloprid concentration, exposure duration, and water temperature on marbled crayfish Procambarus virginalis. Chemosphere 2020, 273, 128463. [CrossRef]

52. Dsikowitzky, L.; Nguyen, T.M.I.; Konzer, L.; Zhao, H.; Wang, D.R.; Yang, F.; Schwarzbauer, J. Occurrence and origin of triazine herbicides in a tropical coastal area in China: A potential ecosystem threat. Estuarine Coast. Shelf Sci. 2020, 235, 106612. [CrossRef]

53. Biggar, J.W.; Riggs, R.L. Apparent solubility of organochlorine insecticides in water at various temperatures. Hilgardia 1974, 42, 383-391. [CrossRef]

54. Lopes, T.O.M.; Passos, L.S.; Vieira, L.V.; Pinto, E.; Dorr, F.; Scherer, R.; Salustriano, N.D.A.; Carneiro, M.T.W.D.; Postay, L.F.; Gomes, L.C. Metals, arsenic, pesticides, and microcystins in tilapia (Oreochromis niloticus) from aquaculture parks in Brazil. Environ. Sci. Pollut. Res. 2020, 27, 20187-20200. [CrossRef] [PubMed]

55. Dawood, M.A.O.; Abdel-Tawwab, M.; Abdel-Latif, H.M. Lycopene reduces the impacts of aquatic environmental pollutants and physical stressors in fish. Rev. Aquac. 2020, 12, 2511-2526. [CrossRef]

56. Magouz, F.I.; Dawood, M.A.O.; Salem, M.F.I.; El-Ghandour, M.; van Doan, H.; Mohamed, A.A.I. The role of a digestive enhancer in improving the growth performance, digestive enzymes activity, and health condition of Nile tilapia (Oreochromis niloticus) reared under suboptimal temperature. Aquaculture 2020, 526, 735388. [CrossRef]

57. Azimirad, M.; Meshkini, S.; Ahmadifard, N.; Hoseinifar, S.H. The effects of feeding with synbiotic (Pediococcus acidilactici and fructooligosaccharide) enriched adult Artemia on skin mucus immune responses, stress resistance, intestinal microbiota and performance of angelfish (Pterophyllum scalare). Fish Shellfish. Immunol. 2016, 54, 516-522. [CrossRef] [PubMed]

58. Song, S.K.; Beck, B.R.; Kim, D.; Park, J.; Kim, J.; Kim, H.D.; Ringø, E. Prebiotics as immunostimulants in aquaculture: A review. Fish Shellfish. Immunol. 2014, 40, 40-48. [CrossRef]

59. Rjeibi, I.; Ben Saad, A.; Hfaiedh, N. Oxidative damage and hepatotoxicity associated with deltamethrin in rats: The protective effects of Amaranthus spinosus seed extract. Biomed. Pharmacother. 2016, 84, 853-860. [CrossRef]

60. Guzman-Villanueva, L.T.; Tovar-Ramírez, D.; Gisbert, E.; Cordero, H.; Guardiola, F.A.; Cuesta, A.; Meseguer, J.; Ascencio-Valle, F.; Esteban, M.A. Dietary administration of $\beta-1,3 / 1,6$-glucan and probiotic strain Shewanella putrefaciens, single or combined, on gilthead seabream growth, immune responses and gene expression. Fish Shellfish. Immunol. 2014, 39, 34-41. [CrossRef]

61. Aliko, V.; Qirjo, M.; Sula, E.; Morina, V.; Faggio, C. Antioxidant defense system, immune response and erythron profile modulation in gold fish, Carassius auratus, after acute manganese treatment. Fish Shellfish. Immunol. 2018, 76, 101-109. [CrossRef]

62. Yao, J.; Wang, J.-Y.; Liu, L.; Li, Y.-X.; Xun, A.-Y.; Zeng, W.-S.; Jia, C.-H.; Wei, X.-X.; Feng, J.-L.; Zhao, L.; et al. Anti-oxidant Effects of Resveratrol on Mice with DSS-induced Ulcerative Colitis. Arch. Med. Res. 2010, 41, 288-294. [CrossRef]

63. Sala, A.; Recio, M.; Schinella, G.R.; Máñez, S.; Giner, R.M.; Cerdá-Nicolás, M.; Ríos, J.-L. Assessment of the anti-inflammatory activity and free radical scavenger activity of tiliroside. Eur. J. Pharmacol. 2003, 461, 53-61. [CrossRef]

64. Petit, J.; Wiegertjes, G.F. Long-lived effects of administering $\beta$-glucans: Indications for trained immunity in fish. Dev. Comp. Immunol. 2016, 64, 93-102. [CrossRef]

65. Ahmadifar, E.; Sadegh, T.H.; Dawood, M.A.; Dadar, M.; Sheikhzadeh, N. The effects of dietary Pediococcus pentosaceus on growth performance, hemato-immunological parameters and digestive enzyme activities of common carp (Cyprinus carpio). Aquaculture 2020, 516, 734656. [CrossRef]

66. Ming, J.; Xie, J.; Xu, P.; Liu, W.; Ge, X.; Liu, B.; He, Y.; Cheng, Y.; Zhou, Q.; Pan, L. Molecular cloning and expression of two HSP70 genes in the Wuchang bream (Megalobrama amblycephala Yih). Fish Shellfish. Immunol. 2010, 28, 407-418. [CrossRef] [PubMed]

67. Lindquist, S.; Craig, E.A. The Heat-Shock Proteins. Annu. Rev. Genet. 1988, 22, 631-677. [CrossRef]

68. Forsyth, R.B.; Candido, E.P.M.; Babich, S.L.; Iwama, G.K. Stress Protein Expression in Coho Salmon with Bacterial Kidney Disease. J. Aquat. Anim. Health 1997, 9, 18-25. [CrossRef]

69. Voll, R.E.; Herrmann, M.; Roth, E.A.; Stach, C.; Kalden, J.R.; Girkontaite, I. Immunosuppressive effects of apoptotic cells. Nature 1997, 390, 350-351. [CrossRef]

70. Van Doan, H.; Hoseinifar, S.H.; Tapingkae, W.; Seel-Audom, M.; Jaturasitha, S.; Dawood, M.A.; Wongmaneeprateep, S.; Thu, T.T.N.; Esteban, M.Á. Boosted growth performance, mucosal and serum immunity, and disease resistance Nile tilapia (Oreochromis niloticus) fingerlings using corncob-derived xylooligosaccharide and Lactobacillus plantarum CR1T5. Probiotics Antimicrob. Proteins 2020, 12, 400-411. [CrossRef]

71. Yang, P.; Yang, W.; He, M.; Li, X.; Leng, X.-J. Dietary synbiotics improved the growth, feed utilization and intestinal structure of largemouth bass (Micropterus salmoides) juvenile. Aquac. Nutr. 2020, 26, 590-600. [CrossRef] 
72. Hoseinifar, S.H.; Yousefi, S.; van Doan, H.; Ashouri, G.; Gioacchini, G.; Maradonna, F.; Carnevali, O. Oxidative Stress and Antioxidant Defense in Fish: The Implications of Probiotic, Prebiotic, and Synbiotics. Rev. Fish. Sci. Aquac. 2020, $29,1-20$. [CrossRef]

73. Sherif, A.H.; Mahfouz, M.E. Immune status of Oreochromis niloticus experimentally infected with Aeromonas hydrophila following feeding with 1, $3 \beta$-glucan and levamisole immunostimulants. Aquaculture 2019, 509, 40-46. [CrossRef]

74. Cavalcante, R.B.; Telli, G.S.; Tachibana, L.; Dias, D.D.C.; Oshiro, E.; Natori, M.M.; da Silva, W.F.; Ranzani-Paiva, M.J. Probiotics, Prebiotics and Synbiotics for Nile tilapia: Growth performance and protection against Aeromonas hydrophila infection. Aquac. Rep. 2020, 17, 100343. [CrossRef]

75. Dawood, M.A.O. Nutritional immunity of fish intestines: Important insights for sustainable aquaculture. Rev. Aquac. 2021, 13, 642-663. [CrossRef] 